\title{
The Effect of Inhaled Nitric Oxide on the Pulmonary Circulation of the Neonatal Pig
}

\author{
LEIF D. NELIN, JAMIL MOSHIN, CAROL J. THOMAS, P. SASIDHARAN, AND \\ CHRISTOPHER A. DAWSON \\ Departments of Pediatrics [L.D.N., J.M., C.J.T., P.S.] and Physiology [C.A.D.], Medical College of Wisconsin, \\ Milwaukee, Wisconsin 53226 and Research Service [L.D.N., C.J.T., C.A.D.], \\ Zablocki VAMC, Milwaukee, Wisconsin 53295
}

\begin{abstract}
To study the pulmonary vasodilator selectivity of low levels of inhaled nitric oxide (NO) in a model of neonatal pulmonary hypertension, we sequentially exposed anesthetized, spontaneously breathing neonatal pigs to each of four different inspired gas mixtures: room air, room air with 25 parts per million NO, hypoxia $\left(14 \% \mathrm{O}_{2}\right.$ in $\left.\mathrm{N}_{2}\right)$, and hypoxia with 25 parts per million NO. The room air, room air with NO, hypoxia, and hypoxia with NO exposures were of 15-min duration. The following measurements were made: mean systemic arterial, mean pulmonary arterial, and wedge pressures; thermodilution cardiac output; esophageal pressure; tracheal flow; and arterial $\mathbf{P o}_{2}$, $\mathrm{PCO}_{2}, \mathrm{pH}$, hemoglobin, and methemoglobin. Inhalation of NO decreased pulmonary arterial pressure in both room air and hypoxia conditions (mean pulmonary arterial pressure $16 \pm 1$ torr room air, $13 \pm 1$ torr room air with NO, $p<0.005$; and mean pulmonary arterial pressure $21 \pm 2$ torr hypoxia, $14 \pm 1$ torr hypoxia with NO, $p<0.005$ ). NO had no significant effect on systemic arterial pressure, cardiac output, dynamic lung compliance, pulmonary resistance, or the measured blood variables during either control or hypoxic conditions. The results indicate that inhaled NO was a selective pulmonary vasodilator that could effectively reverse acute hypoxic pulmonary vasoconstriction. The normoxic vasodilation produced by NO inhalation also indicates the existence of basal vasomotor tone in the anesthetized, spontaneously breathing neonatal pig. The short-term exposures used produced no detectable manifestations of toxic side effects. (Pediatr Res 35: 2024, 1994)
\end{abstract}

\section{Abbreviations}

NO, nitric oxide

PVR, pulmonary vascular resistance

PPHN, persistent pulmonary hypertension of the newborn

Neonatal pulmonary diseases, such as surfactant deficiency, PPHN, and bronchopulmonary dysplasia, often present with pulmonary hypertension and remain an important cause of morbidity and mortality in infants admitted to neonatal intensive care unit. No uniformly efficacious therapy exists for pulmonary hypertension despite many trials of various vasodilators, including tolazoline; chlorpromazine; nifedipine; verapamil; sodium nitroprusside; amrinone; fentanyl; sodium bicarbonate; neuro-

Received April 12, 1993; accepted August 17, 1993.

Correspondence to: Leif D Nelin, MD. Research Service 151, Zablocki VAMC 5000 West National Avenue, Milwaukee, WI 53295-1000.

Extramural support from NHLBI HL-19298 and the Department of Veterans Affairs. muscular blockers; and the prostaglandins $I_{2}, E_{1}$, and $D_{2}(1)$. An efficacious therapy would be one that resulted in a sustained decrease in pulmonary artery pressure with no change in systemic blood pressure and no change or an increase in cardiac output. Many of the vasodilators that have been used in adults with primary pulmonary hypertension were developed for the treatment of systemic hypertension, and none has proved to be a sufficiently selective pulmonary vasodilator (2). In fact, the dose of the vasodilator is usually titrated until a predetermined fall in systemic blood pressure occurs $(1,2)$. The search for a selective pulmonary vasodilator has recently centered on the endothelial cell. NO has been shown to have an important role in the vasodilator response to a wide variety of agents (3-5), which has led to the concept that the administration of exogenous NO may have therapeutic potential in the treatment of pulmonary hypertensive diseases. The reaction of $\mathrm{NO}$ with hemoglobin inactivates the vasodilator effects of NO (6), and the reaction with hemoglobin is so rapid (7) that NO is probably not a generally useful blood-borne vasodilator. For the pulmonary circulation, wherein NO can be delivered via the inspired air, the rapid reaction with hemoglobin may be an advantage in that inactivation in the blood could limit its vasodilator effect to those vessels that are in close apposition to the air space. For example, Frostell et al. (8) found that inhaled NO reversed hypoxic pulmonary vasoconstriction without causing systemic vasodilation. Furthermore, studies on isolated airway segments suggest that NO may be a bronchodilator (9). Thus inhaled NO may be particularly beneficial in lung diseases that are characterized by both vasoconstriction and bronchoconstriction, such as bronchopulmonary dysplasia. However, the enthusiasm for the therapeutic use of NO in pulmonary hypertensive disease must be tempered by the consideration of the potential for toxic side effects.

The aim of this study in neonatal animals was to determine the efficacy of inhaled NO as a selective pulmonary vasodilator and the effects of inhaled NO on lung mechanics and methemoglobin formation. Measurements were obtained during 15min exposures to room air, to room air with 25 parts per million (ppm) NO, to hypoxia, and to hypoxia with $25 \mathrm{ppm}$ NO. The neonatal pig was chosen because the pig lung has a similar postnatal morphologic development when compared with the human lung (10), and it has been used extensively as an animal model in studies of sepsis-induced PPHN (11-14). Studies of the efficacy of short-term exposure to NO were deemed necessary before embarking on long-term exposures such as might be relevant to the clinical setting. An important objective of this research was to develop a model for future study of the effects of longer term exposure to NO in a relevant neonatal animal.

\section{MATERIALS AND METHODS}

Seven neonatal pigs [age $13 \pm 2(\mathrm{SD}) \mathrm{d}$, wt $3.8 \pm 0.6 \mathrm{~kg}$ ] were studied while breathing spontaneously. The pigs were anesthe- 
tized with a mixture of acepromazine $(1.5 \mathrm{mg} / \mathrm{kg})$ and ketamine $(30 \mathrm{mg} / \mathrm{kg})$ given intramuscularly and then placed in the supine position on a servo-controlled heating blanket. Catheters were placed in the inferior vena cava via the femoral vein and in the descending aorta via the femoral artery. Sodium pentobarbital $(4 \mathrm{mg} / \mathrm{kg})$ was administered i.v. every hour to maintain anesthesia. A tracheostomy was performed, and a $5 \mathrm{Fr}$ Swan-Ganz catheter was advanced into a branch of the pulmonary artery via the right external jugular vein. The position of the Swan-Ganz catheter was determined with the pressure waveform recorded from the distal tip of the catheter and confirmed at autopsy.

The mean pulmonary arterial $(\mathrm{Pa})$ and mean systemic arterial pressures were measured continuously, and the pulmonary wedge (Pw) pressure was measured during each experimental condition. Cardiac output was measured by the bolus injection of $2 \mathrm{~mL}$ of iced saline into the femoral venous line, and the thermodilution cardiac output was calculated using a cardiac output computer (model 9520, American Edwards, Santa Ana, CA). The reported values for cardiac output are the average of three injections under each condition. PVR was calculated as

$$
\text { PVR }=\frac{(\mathrm{Pa}-\mathrm{Pw})}{\text { Cardiac output }}
$$

The tracheostomy tube was attached to a pneumotachograph. The flow signal was recorded and also integrated for the determination of volume. An esophageal balloon was placed in the lower one-third of the esophagus for measurement of pressure. The flow, volume, and esophageal pressure signals were digitized at $50 \mathrm{~Hz}$ and used to calculate dynamic compliance and pulmonary resistance using the method of Dennis et al. (15).

Arterial blood gases were determined using a blood gas analyzer (Ciba-Corning model 278, Corning Medical, Medfield, MA). Hemoglobin concentration was quantified using the standard cyanomethemoglobin method. Hematocrit was determined in the standard fashion. Methemoglobin was determined in triplicate by the method of Fairbanks and Klee (16). Briefly, 0.1 $\mathrm{mL}$ of blood was hemolyzed using distilled water, and then 4 $\mathrm{mL}$ of a phosphate buffer ( $\mathrm{pH}$ 6.6) was added. Three $\mathrm{mL}$ of this solution was divided between two cuvettes $\left(C_{2}\right.$ and $\left.C_{3}\right)$. To $C_{3}$, $0.1 \mathrm{ml}$ of $0.6 \mathrm{M}$ potassium ferricyanide was added, and after 2 min the absorbance of $C_{2}$ and $C_{3}$ were read at $630 \mathrm{~nm}\left(A_{2 a}\right.$ and $A_{3 a}$, respectively). Then $0.1 \mathrm{~mL}$ of $0.8 \mathrm{M}$ potassium cyanide was added to both $C_{2}$ and $C_{3}$, and the absorbance was read at 630 $\mathrm{nm}$ ( $A_{2 b}$ and $A_{3 b}$, respectively). The phosphate buffer was used as the blank for all absorbance readings. The percentage methemoglobin $(\% \mathrm{Mb})$ was then

$$
\% \mathrm{Mb}=100\left(\frac{\mathrm{A}_{2 \mathrm{a}}-\mathrm{A}_{2 \mathrm{~b}}}{\mathrm{~A}_{3 \mathrm{a}}-\mathrm{A}_{3 \mathrm{~b}}}\right)
$$

Nitric oxide gas was synthesized according to the method described by Schenk (17). Briefly, alternate layers of $8.5 \mathrm{~g}$ of finely ground anhydrous ferrous sulfate and a finely pulverized mixture of $8.5 \mathrm{~g}$ of sodium bromide and $4 \mathrm{~g}$ of sodium nitrite were placed in a dry, 100-mL round bottom flask. One drop of distilled water was added to initiate the reaction, and then the flask was shaken and the gas collected in a gas syringe after discarding the first $100 \mathrm{~mL}$ of gas. The NO was always handled in a hood to avoid exposing personnel to either $\mathrm{NO}$ or $\mathrm{NO}_{2}$.

Four gas mixtures were used: $21 \% \mathrm{O}_{2}$ in $\mathrm{N}_{2}$, which we termed room air, room air with $25 \mathrm{ppm}$ NO (referred to as room air with $\mathrm{NO}$ ), $14 \% \mathrm{O}_{2}$ in $\mathrm{N}_{2}$, which we termed hypoxia, and hypoxia with 25 ppm NO (referred to as hypoxia with NO). The room air and hypoxia gas mixtures were made with calibrated flow meters and stored in gas bags. The room air with NO and hypoxia with NO gas mixtures were made by first filling a gas bag with the appropriate volumes of $\mathrm{N}_{2}$ and then adding the appropriate volume of NO using a gas syringe. Finally, the appropriate volume of $\mathrm{O}_{2}$ was added within 10 min of use with a calibrated flow meter. The bags were always filled in this manner to avoid exposing high concentrations of $\mathrm{NO}$ to $\mathrm{O}_{2}$ and thus avoid the oxidation of $\mathrm{NO}$ to $\mathrm{NO}_{2}$. The $\mathrm{NO}_{2}$ concentrations of the room air with NO and hypoxia with NO bags were measured over time using the technique described by Saltzman (18). Less than $1 \mathrm{ppm}$ $\mathrm{NO}_{2}$ was present in the room air with $\mathrm{NO}$ and hypoxia with NO bags even after $5 \mathrm{~h}$. The gas mixtures were administered via a nonrebreathing valve that was attached to the pneumotachograph. The exhaled gas was collected for determination of $\mathrm{CO}_{2}$ and $\mathrm{O}_{2}$ concentrations. The exhaled concentrations of $\mathrm{CO}_{2}$ and $\mathrm{O}_{2}$ were then used to calculate $\mathrm{O}_{2}$ uptake, $\mathrm{CO}_{2}$ production, and, along with the arterial $\mathrm{PCO}_{2}$, the physiologic dead space.

While the pig was spontaneously breathing, hemodynamic measurements, lung mechanics measurements, and arterial blood samples were obtained during baseline conditions with room air being breathed. The breathing gas was then changed to room air with NO. After $15 \mathrm{~min}$, the measurements described above were repeated, and the gas was changed to room air. After it was on room air for 2 or $3 \mathrm{~min}$, when pulmonary artery pressure had stabilized at the baseline value, the gas was switched to hypoxia. After the gas was on hypoxia for $15 \mathrm{~min}$, the measurements described above were repeated, and the gas was changed to hypoxia with NO. After $15 \mathrm{~min}$ the measurements described above were repeated. We have previously found that the neonatal pig has a stable hypoxic response over this time period (19). Finally, the pig breathed room air, and after 2 or 3 min, when the pulmonary artery pressure had stabilized at the baseline value, the pig was exsanguinated and the lungs removed for the determination of wet-to-dry weight ratios.

The data are presented as the mean \pm SEM. The $t$ test for paired data was used to compare the changes that occurred during the different experimental conditions. The $p$ values are given when $p<0.05$. In making the three comparisons we are interested in (i.e. room air to room air with NO, hypoxia to hypoxia with NO, and room air to hypoxia), the Bonferroni method indicates a significance level of $p<0.017$ for rejecting the null hypothesis.

\section{RESULTS}

In the spontaneously breathing neonatal pig, reducing the inspired oxygen tension produced a significant decrease in $\mathrm{PO}_{2}$ in the two hypoxic conditions compared with the two room air conditions. Otherwise, no significant change occurred in $\mathrm{PO}_{2}$, $\mathrm{PCO}_{2}$, or $\mathrm{pH}$ between room air and room air with $\mathrm{NO}$ or between hypoxia and hypoxia with NO. The mean of the pulmonary arterial pressure tracing for all seven animals is shown in Figure 1. Each of the seven pigs responded in a similar fashion, that is, when $25 \mathrm{ppm}$ NO was added to the room air mixture, a decrease in mean pulmonary arterial pressure occurred, and when the gas mixture was changed to the hypoxia mixture an increase in mean pulmonary arterial pressure occurred. Furthermore, this hypoxia-induced increase in mean pulmonary arterial pressure was essentially reversed by adding $25 \mathrm{ppm}$ NO to the hypoxic gas mixture in each pig studied. Because these changes in mean pulmonary arterial pressure occurred with no significant changes in cardiac output or wedge pressure (Table 1), the changes in mean pulmonary arterial pressure reflect changes in PVR (also given in Table 1). The pattern of the PVR response in each individual animal was also the same as the mean response. Figure 2 shows the mean for all seven animals for the pulmonary and systemic hemodynamic responses after $15 \mathrm{~min}$ in each condition. Again, it can be seen that adding NO to the inspired gas mixture caused pulmonary vasodilation under both baseline and hypoxic conditions. This representation of the data emphasizes that no significant systemic effects were detected.

Tidal volume, minute ventilation, dead space, respiratory rate, oxygen uptake, and carbon dioxide production were unaffected by the experimental condition (Table 1). Inhaled NO (25 ppm) had no significant effect on the airways during either control or hypoxic conditions, as evidenced by no significant change in either dynamic lung compliance or pulmonary resistance (Table 


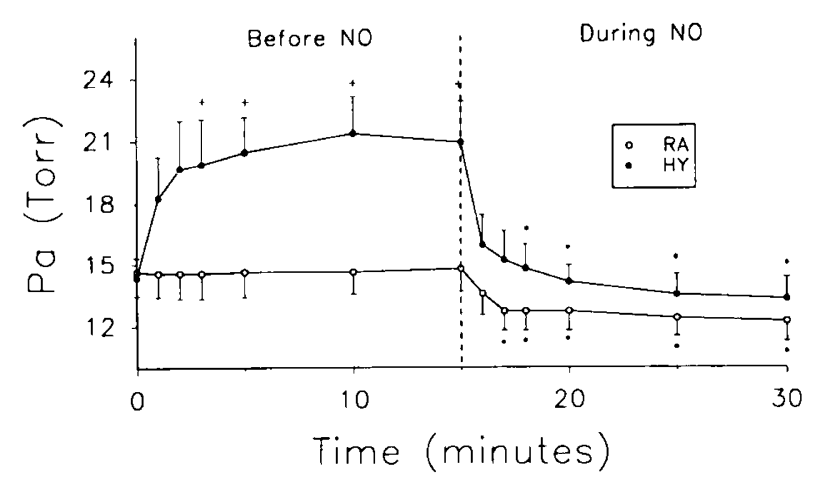

Fig. 1. The mean pulmonary arterial pressure $(\mathrm{Pa})$ during each experimental condition. Open circles represent data obtained during ventilation with the room air $(R A)$ gas mixture, and closed circles represent data obtained during ventilation with the hypoxic $(H Y)$ gas mixture. Dashed line represents the point at which the ventilating gas mixture was changed to the mixture containing $25 \mathrm{ppm}$ NO. Thus the first $15 \mathrm{~min}$ represent the control periods before NO inhalation, and the second 15 min represent the period during which NO was included in the inspired gas. * indicates that during NO the values were different from the before NO values $(p<0.04)$. + indicates that during hypoxia the values were different from the room air values $(p<0.01)$.

1). The values presented in Table 1 were stable during the course of the experiment and are comparable to values previously reported in neonatal pigs (20-23). As a positive control in two animals at the end of the experiment, $0.3 \mathrm{mg} / \mathrm{kg}$ neostigmine was given i.v., which resulted in a doubling of pulmonary resistance from $4.0 \pm 1.1 \mathrm{~cm} \mathrm{H} / 2 / \mathrm{mL} / \mathrm{s}$ baseline to $7.8 \pm 2.8 \mathrm{~cm}$ $\mathrm{H}_{2} \mathrm{O} / \mathrm{mL} / \mathrm{s}$ after neostigmine administration.

Table 1 also shows that no significant changes occurred in the hemoglobin, hematocrit, or methemoglobin levels during any of the 15 -min experimental conditions or during the course of the study. As a positive control in one animal at the end of the experiment, $1000 \mathrm{ppm}$ NO in room air was administered for 15 min, which resulted in an increase in the methemoglobin fraction to $20 \%$ of the total hemoglobin.
At the end of the experiment, the lung wet wt averaged 46.0 $\pm 8.3 \mathrm{~g}$, the dry wt averaged $8.7 \pm 1.3 \mathrm{~g}$, and the wet-to-dry ratio averaged $5.2 \pm 0.2$.

\section{DISCUSSION}

We found that 25 ppm NO reversed the hypoxic vasoconstriction with no significant effect on either cardiac output or systemic blood pressure. Thus, at least for the short exposure time involved in these studies, inhaled NO was a selective pulmonary vasodilator in these neonatal pigs. These results are consistent with findings from both neonatal pigs (24) that had ventilation with $150 \mathrm{ppm}$ NO and neonatal $(8,25)$ and premature lambs $(26)$ that had ventilation with $20 \mathrm{ppm}$ NO. Contrary to the observations on the influence of NO ventilation in the neonatal lamb (8), in our neonatal pigs, NO consistently produced vasodilation under normoxic conditions as well. This finding indicates that the pulmonary vessels of these anesthetized, spontaneously breathing neonatal pigs had some level of vasomotor tone under these conditions. This result is consistent with the findings of Bradley et al. (27) in the neonatal pig ( $<10 \mathrm{~d}$ old) with ketamine and pentobarbital anesthesia, and mechanical ventilation, wherein the infusion of endothelin resulted in a significant decrease in PVR (mean pulmonary arterial pressure $16 \pm 1$ torr control and $13 \pm 1$ torr endothelin) with no change in cardiac output $(0.6 \pm 0.1 \mathrm{~L} / \mathrm{min}$ control and $0.5 \pm 0.1 \mathrm{~L} / \mathrm{min}$ endothelin). Studies from isolated, perfused neonatal pig lungs also suggest the presence of basal vasomotor tone. For example, Fike and Kaplowitz (28) found that injection of papaverine resulted in a decrease in PVR in neonatal pig lungs, and we found that infusion of acetylcholine decreased PVR in a similar preparation (19). These differences between pigs and lambs may suggest possible species differences in the level of basal pulmonary vasomotor tone. The existence of such species differences is consistent with a recent study wherein pigs had higher tone at a partial pressure of oxygen in the alveoli of 110 torr than either horses or dogs (29). On the other hand, the differences might reflect other experimental aspects, such as different anesthetic regimens. Although Worek et al. (30) found that ketamine or pentobarbital anesthesia did not affect hemodynamics in intact

Table 1. Physiologic variables*

\begin{tabular}{|c|c|c|c|c|}
\hline & Room air & $\begin{array}{l}\text { Room air } \\
\text { with NO }\end{array}$ & Hypoxia & $\begin{array}{l}\text { Hypoxia } \\
\text { with NO }\end{array}$ \\
\hline $\mathrm{Pa}$ (torr) & $16 \pm 1$ & $13 \pm 1 \dagger$ & $21 \pm 2 \dagger$ & $14 \pm 1 \ddagger$ \\
\hline Pw (torr) & $2 \pm 1$ & $2 \pm 1$ & $2 \pm 1$ & $2 \pm 1$ \\
\hline Psys (torr) & $68 \pm 3$ & $68 \pm 3$ & $70 \pm 5$ & $67 \pm 6$ \\
\hline Cardiac output (L/min) & $2.0 \pm 0.1$ & $1.9 \pm 0.1$ & $2.0 \pm 0.2$ & $1.9 \pm 0.2$ \\
\hline PVR (torr $/ \mathrm{L} / \mathrm{min}$ ) & $7.0 \pm 0.6$ & $6.0 \pm 0.6 \dagger$ & $9.8 \pm 1.1 \dagger$ & $6.8 \pm 0.8 \ddagger$ \\
\hline $\mathrm{C}\left(\mathrm{mL} / \mathrm{cm} \mathrm{H}_{2} \mathrm{O}\right)$ & $10.2 \pm 2.8$ & $10.9 \pm 2.8$ & $11.3 \pm 2.9$ & $12.1 \pm 3.1$ \\
\hline $\mathrm{R}_{\mathrm{L}}\left(\mathrm{cm} \mathrm{H} \mathrm{H}_{2} \mathrm{O} / \mathrm{L} / \mathrm{s}\right)$ & $5.2 \pm 1.3$ & $4.9 \pm 1.5$ & $5.9 \pm 1.9$ & $6.3 \pm 2.3$ \\
\hline $\mathrm{V}_{\mathrm{t}}(\mathrm{mL})$ & $35 \pm 8$ & $35 \pm 8$ & $37 \pm 9$ & $37 \pm 10$ \\
\hline$\dot{\mathrm{V}}_{\mathrm{E}}(\mathrm{L} / \mathrm{min})$ & $2.4 \pm 0.6$ & $2.6 \pm 0.7$ & $2.9 \pm 0.7$ & $2.9 \pm 0.7$ \\
\hline $\mathrm{V}_{\mathrm{D}}(\mathrm{mL})$ & $11 \pm 1$ & $11 \pm 2$ & $13 \pm 2$ & $12 \pm 2$ \\
\hline$f\left(\min ^{-1}\right)$ & $74 \pm 10$ & $76 \pm 10$ & $81 \pm 7$ & $85 \pm 8$ \\
\hline$\dot{\mathrm{V}}_{2}(\mathrm{~mL} / \mathrm{min})$ & $51 \pm 11$ & $53 \pm 11$ & $47 \pm 12$ & $46 \pm 10$ \\
\hline $\mathrm{V}_{\mathrm{CO}_{2}}(\mathrm{~mL} / \mathrm{min})$ & $46 \pm 10$ & $48 \pm 10$ & $48 \pm 11$ & $49 \pm 10$ \\
\hline $\mathbf{R}$ & $0.90 \pm 0.03$ & $0.91 \pm 0.02$ & $1.06 \pm 0.07$ & $1.09 \pm 0.09$ \\
\hline $\mathrm{PO}_{2}(\mathrm{kPa})$ & $10.8 \pm 0.4$ & $10.4 \pm 0.5$ & $5.9 \pm 0.4 \dagger$ & $6.9 \pm 0.5 \dagger$ \\
\hline $\mathrm{PCO}_{2}(\mathrm{kPa})$ & $4.7 \pm 0.1$ & $4.4 \pm 0.1$ & $4.3 \pm 0.1$ & $3.9 \pm 0.1$ \\
\hline $\mathrm{pH}$ & $7.36 \pm 0.01$ & $7.39 \pm 0.02$ & $7.38 \pm 0.02$ & $7.38 \pm 0.02$ \\
\hline $\mathrm{Hb}(\mathrm{g} / \mathrm{L})$ & $38 \pm 1$ & $43 \pm 4$ & $43 \pm 1$ & $40 \pm 3$ \\
\hline $\mathrm{Hct}$ & $0.17 \pm 0.02$ & $0.15 \pm 0.01$ & $0.15 \pm 0.01$ & $0.15 \pm 0.01$ \\
\hline $\mathrm{Mb}(\% \mathrm{Hb})$ & $4.6 \pm 2.3$ & $4.1 \pm 2.2$ & $3.2 \pm 1.4$ & $4.8 \pm 1.6$ \\
\hline
\end{tabular}

* Values are expressed as mean \pm SEM. Pa, pulmonary arterial pressure; Pw, pulmonary wedge pressure; Psys, systemic arterial pressure; $\mathrm{C}$ dynamic lung compliance; $R_{L}$, pulmonary resistance; $V_{1}$, tidal volume; $\dot{V}_{E}$, minute ventilation; $V_{D}$, dead space; $f$, respiratory rate; $\dot{V}_{2}$, oxygen uptake; $\mathrm{V}_{\mathrm{CO}_{2}}$, carbon dioxide production; $\mathrm{R}$, respiratory exchange ratio; Hb, hemoglobin; Hct, hematocrit; Mb, methemoglobin.

+ Different from room air $p<0.005$.

$\ddagger$ Different from hypoxia $p<0.005$. 


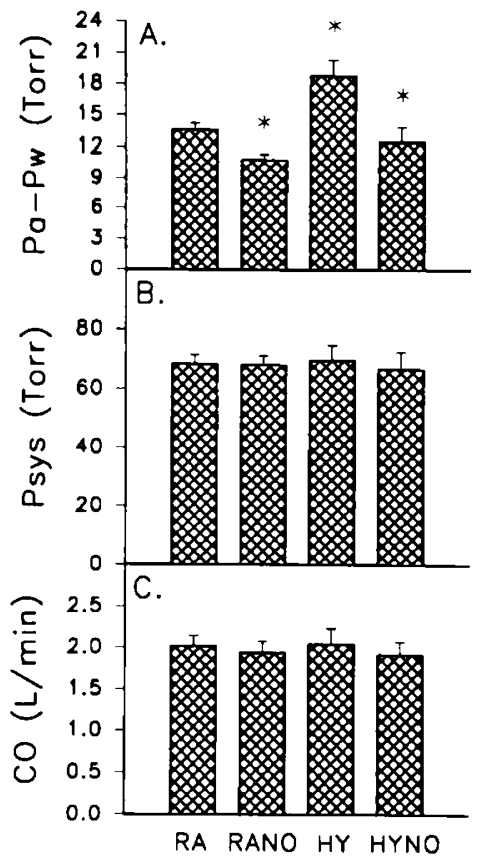

Fig. 2. $(A)$ The mean pulmonary arterial pressure-pulmonary wedge pressure $(P a-P w),(B)$ the mean systemic arterial pressure $(P s y s)$, and $(C)$ the mean cardiac output $(C O)$ at the end of $15 \mathrm{~min}$ in each experimental condition. * represents different from the preceding condition $(p<0.005)$. $R A$, room air; $R A N O$, room air with NO; $H Y$, hypoxia; $H Y N O$, hypoxia with NO.

pigs, previous investigators $(10,11,13)$ have reported baseline mean pulmonary arterial pressure-pulmonary wedge pressure in neonatal pigs ranging from $10 \pm 4$ to $16 \pm 4$ torr, similar to those reported in this study.

The selectivity of inhaled NO may be caused in part by its normally short $t_{1 / 2}$ in solution, which has been reported to be approximately $4 \mathrm{~s}$ in oxygenated, hemoglobin-free media (6). This period of time is on the order of the transit time from the pulmonary veins to the systemic arteries, and thus not much NO would be expected to survive the transit. However in addition, NO reaching the blood will rapidly combine with hemoglobin (7). The NO binding affinity for hemoglobin is much greater than that of either $\mathrm{O}_{2}$ or $\mathrm{CO}$, and the reaction rate of $\mathrm{NO}$ with hemoglobin is faster than that of either $\mathrm{CO}$ or $\mathrm{O}_{2}$ with hemoglobin (7). Thus any NO reaching the blood would be rapidly inactivated, and the action of NO would be essentially limited to those vascular smooth muscle cells that were in close apposition to alveolar air.

One concern for potential lung toxicity of inhaled NO is based on the propensity of $\mathrm{NO}$ to be converted to $\mathrm{NO}_{2}$ in the presence of oxygen (31). $\mathrm{NO}_{2}$ is classified as a deadly poison and is highly toxic to the lungs (32), and exposure to $\mathrm{NO}_{2}$ rapidly leads to increased airway resistance, pulmonary edema, and bronchopneumonia, which may develop into bronchiolitis obliterans (33). Stavert and Lehnert (31) found increases in lung gravimetric measurements after a $30-\mathrm{min}$ exposure to $50 \mathrm{ppm} \mathrm{NO}$. Müller et al. (34) found that exposure to only $10 \mathrm{ppm} \mathrm{NO}_{2}$ in adult rats for $72 \mathrm{~h}$ led to a severe interstitial infiltrate and alveolar exudate. The lung wet weights measured in our study suggest little or no accumulation of extravascular fluid during the experimental protocol when compared with published results $(20,28)$.

NO has been reported to relax isolated tracheal rings (9), and recently we found that inhaled NO $(25 \mathrm{ppm})$ resulted in a decrease in pulmonary resistance in the neonatal pig lung preconstricted with neostigmine (35). In the present study, we did not detect a change in pulmonary resistance in association with inhalation of the NO, a result consistent with that of Zayek et al. (36) in neonatal lambs. This finding may be because these animals had little basal airway smooth muscle tone or because the NO concentration was insufficient. Thus this study does not provide conclusive information regarding this aspect of the possible impact of $\mathrm{NO}$ inhalation. On the other hand, $\mathrm{NO}_{2}$ is an irritant gas that can cause bronchoconstriction $(33,37-39)$. The lack of a detectable bronchoconstrictor effect suggests that if any conversion of $\mathrm{NO}$ to $\mathrm{NO}_{2}$ occurred within the airways it was not sufficient to manifest itself in this manner.

In the present short-term study, wherein inspired gas $\mathrm{NO}_{2}$ contamination does not appear to have been a problem, it is not surprising that the various manifestations of $\mathrm{NO}_{2}$ toxicity were not detected. However, under the conditions encountered in the intensive care nursery, inhaled NO might have to be administered for at least $3 \mathrm{~d}$ and perhaps as many as $14 \mathrm{~d}$ and with elevated inspired $\mathrm{PO}_{2}$. Under such conditions the possibility that inhaled NO might be associated with these and other toxic effects of $\mathrm{NO}_{2}$ inhalation, such as decreased resistance to respiratory infections (37), will need to be evaluated. The latter may have implications in the use of inhaled NO for the treatment of infectious causes of PPHN such as group B streptococcus.

Some evidence exists that inhaled NO itself may cause lung toxicity without conversion to $\mathrm{NO}_{2}$, but this is less clear. Stavert and Lehnert (31) found that when NO was given without contamination by $\mathrm{NO}_{2}$ there was no histologic evidence of lung damage with $15-\mathrm{min}$ exposures of up to $1500 \mathrm{ppm}$. In mice it was found that long-term exposure ( $2 \mathrm{wk}$ ) to $10 \mathrm{ppm}$ NO led to increased lung weight and morphologic evidence of lung damage (40). Because NO has a single unpaired electron (41), it has been suggested that it may be involved in free radical injury to the lung. Conversion to the highly toxic peroxynitrite anion is one possibility (42-44). This potential for free radical injury might be of particular concern in the treatment of PPHN in patients receiving high concentrations of supplemental oxygen.

A potential systemic toxic effect of inhaled NO is the formation of methemoglobin. NO and its immediate oxidation product, nitrite ion, react with hemoglobin to form methemoglobin. Toothill (45) found that exposure of adult dogs to $1000 \mathrm{ppm}$ to $2000 \mathrm{ppm}$ NO resulted in death within $4 \mathrm{~h}$ as a result of methemoglobinemia. Stavert and Lehnert (31) found that $55 \%$ of rats exposed to $1000 \mathrm{ppm}$ NO for $30 \mathrm{~min}$ died during or within $30 \mathrm{~min}$ after the exposure period because of methemoglobinemia. Maeda et al. (46) found that exposure of adult rats to $200 \mathrm{ppm}$ NO for $3 \mathrm{~h}$ resulted in methemoglobin levels of $40 \%$. Recently, increases in methemoglobin levels have been reported in neonatal pigs (24) and neonatal lambs (36) exposed to 150 ppm and $100 \mathrm{ppm}$, respectively, of NO for $30 \mathrm{~min}$. We found no significant change in methemoglobin levels in our pigs during 15-min exposures to inhaled NO. We did not measure the NO uptake in these studies. However, the volume of inhaled NO is a secure upper boundary on the amount of NO that could have entered the blood. Thus, if all of the inspired NO had reacted with hemoglobin, it would have increased the methemoglobin by only about $3 \%$ of the hemoglobin concentration over the 15 min period. Given this point as an upper boundary and the presence of the normal methemoglobin-reducing mechanisms in the blood (45), the lack of an increase in methemoglobin in these short exposures is not a surprising result. However, there may be a dose and time effect of inhaled NO on both the formation of methemoglobin and its reduction to hemoglobin $(24,36,46)$. Therefore further studies will be required to determine methemoglobin formation under conditions similar to those that would be expected in the clinical use of inhaled NO.

In conclusion, we found that in the anesthetized, spontaneously breathing neonatal pig the inhalation of $25 \mathrm{ppm}$ NO caused pulmonary vasodilation under control conditions and reversed hypoxic pulmonary vasoconstriction. This finding suggests that in this preparation basal pulmonary vasomotor tone exists that can be overcome with exogenous NO and that the acute pulmonary vasoconstriction associated with low oxygen ventilation can be reversed by NO administered via the airways. 
The short-term inhalation of 25 ppm NO was not associated with detectable toxic side effects. This finding suggests that further studies into the use of inhaled $\mathrm{NO}$ as a pharmacologic tool in neonatal pulmonary hypertensive diseases such as PPHN are warranted. It appears that the neonatal pig preparation that we describe will be a useful animal model for such studies.

\section{REFERENCES}

1. Philips JB 1990 Treatment of PPHNS. In: Long WA (ed) Fetal and National Cardiology. WB Saunders Company, Philadelphia, pp 691-701

2. Rubin LJ 1990 Vasodilator therapy (general aspects). In: Fishman AP (ed) The Pulmonary Circulation: Normal and Abnormal. University of Pennsylvania Press, Philadelphia, pp 479-483

3. Archer SL, Rist K, Nelson DP, DeMaster EG, Cowan N, Weir EK 1990 Comparison of the hemodynamic effects of nitric oxide and endothelium dependent vasodilators in intact lungs. J Appl Physiol 68:735-747

4. Russ RD, Walker BR 1992 Role of nitric oxide in vasopressinergic pulmonary vasodilation. Am J Physiol 262:H743-H747

5. Ignarro LJ, Harbison RG, Wood KS, Kadowitz PJ 1986 Activation of purified soluble guanylate cyclase by endothelium derived relaxing factor from intrapulmonary artery and vein: stimulation by acetylcholine, bradykinin and arachidonic acid. J Pharmacol Exp Ther 237:893-900

6. Palmer RMJ, Ferrige AG, Moncada S 1987 Nitric oxide release accounts for the biological activity of endothelium-derived relaxing factor. Nature 327:524-526

7. Meyer M, Shuster KD, Schulz H, Mohr M, Piiper J 1990 Pulmonary diffusing capacity for nitric oxide and carbon monoxide determined by rebreathing in dogs. J Appl Physiol 68:2344-2357

8. Frostell C, Fratacci MD, Wain JC, Jones R, Zapol WM 1991 Inhaled nitric oxide: a selective pulmonary vasodilator reversing hypoxic pulmonary vasoconstriction. Circulation 83:2038-2047

9. Munakata M, Masaki Y, Sakuma I, Ukita H, Otsuka Y, Homma Y, Kawakami Y 1990 Pharmacological differentiation of epithelium-derived relaxing factor from nitric oxide. J Appl Physiol 69:665-670

10. Rendas A, Braithwaite M, Reid L 1978 Growth of pulmonary circulation in normal pig-structural analysis and cardiopulmonary function. J Appl Physiol 45:806-817

11. Goldberg RN, Suguihara C, Streitfeld MM, Bancalari A, Clark MR, Bancalari E 1986 Effects of a leukotriene antagonist on the early hemodynamic manifestations of group B streptococcal sepsis in piglets. Pediatr Res 20:1004-1008

12. Bowdy BD, Aziz SM, Marple SL, Yoneda K, Pauly TH, Coonrod JD, Gillespie MN 1990 Organ-specific disposition of group B streptococci in piglets: evidence for a direct interaction with target cells in the pulmonary circulation. Pediatr Res 27:344-348

13. Gibson RL, Redding GJ, Henderson WR, Troug WE 1991 Group B streptococcus induces tumor necrosis factor in neonatal piglets. Am Rev Respir Dis 143:598-604

14. Shook LA, Pauly TN, Horstman SJ, Marple SL, Gillespie MN 1990 Dimethylthiourea reverses sepsis-induced pulmonary hypertension in piglets. Am J Med Sci 300:29-32

15. Dennis MW, Douglas JS, Casby JU, Stolwijk JAJ, Bouhuys A 1969 On-line analog computer for dynamic lung compliance and pulmonary resistance. $J$ Appl Physiol 26:248-254

16. Fairbanks VF, Klee GG 1986 Biochemical aspects of hematology. In: Tietz NW (ed) Textbook of Clinical Chemistry. WB Saunders Company, Philadelphia, pp 1532-1537

17. Schenk PW 1963 Nitric oxide. In: Brauer G (ed) Handbook of Preparative Inorganic Chemistry. Academic Press, New York, pp 485-487

18. Saltzman BE 1954 Colormetric microdetermination of nitrogen dioxide in the atmosphere. Anal Chem 26:1949-1955

19. Nelin LD, Dawson CA 1993 The effect of $\mathrm{N}^{*}$-nitro-L-arginine methylester on hypoxic vasoconstriction in the neonatal pig lung. Pediatr Res 34:349-353

20. Standaert TA, Wilham BE, Mayock DE, Watchko JF, Gibson RL, Woodrum DE 1991 Respiratory mechanics of the piglet during the first month of life. Pediatr Pulmonol 11:294-301

21. Escourrou PJL, Teisseire BP, Herigault RA, Vallez MO, Dupeyrat AJ, Gaultier
C 1988 Mechanism of improvement in pulmonary gas exchange during growth in awake piglets. J Appl Physiol 65:1055-1061

22. Mortola JP, Rezzonico R, Lanthier C 1989 Ventilation and oxygen consumption during acute hypoxia in newborn mammals: a comparative analysis. Respir Physiol 78:31-43

23. Clement MG, Mortola JP, Albertini M, Aguggini G 1986 Effects of vagotomy on respiratory mechanics in newborn and adult pigs. J Appl Physiol 60:19921999

24. Berger JI, Gibson RL, Redding GJ, Standaert TA, Clarke WR, Troug WE 1993 Effect of inhaled nitric oxide during group B streptococcal sepsis in piglets. Am Rev Respir Dis 147:1080-1086

25. Roberts JD, Chen TY, Kawai N, Wain J, Dupuy P, Shimouchi A, Bloch K Polaner D, Zapol WM 1993 Inhaled nitric oxide reverses pulmonary vasoconstriction in the hypoxic and acidotic newborn lamb. Circ Res 72:246254

26. Kinsella JP, McQueston JA, Rosenberg AA, Abman SA 1992 Hemodynamic effects of exogenous nitric oxide in ovine transitional pulmonary circulation. Am J Physiol 263:H875-H880

27. Bradley LM, Czaja JF, Goldstein RE 1990 Circulatory effects of endothelin in newborn piglets. Am J Physiol 259:H1613-H1617

28. Fike CD, Kaplowitz MR 1992 Pulmonary venous pressure increases during alveolar hypoxia in isolated lungs of newborn pigs. J Appl Physiol 73:552556

29. Elliott AR, Steffey EP, Jarvis KA, Marshall BE 1991 Unilateral hypoxic pulmonary vasoconstriction in the dog, pony and miniature swine. Respir Physiol 85:355-369

30. Worek FS, Blumel G, Zeravik J, Zimmerman GJ, Pfeiffer UJ 1988 Comparison of ketamine and pentobarbital anesthesia with the conscious state in a porcine model of pseudomonas aeruginosa septicemia. Acta Anaesthesio Scand 32:509-515

31. Stavert DM, Lehnert BE 1990 Nitric oxide and nitrogen dioxide as inducers of acute pulmonary injury when inhaled at relatively high concentrations for brief periods. Inhal Toxicol 2:53-67.

32. Morrow PE 1984 Toxicological data on NO $_{x}$ : an overview. J Toxicol Environ Health 13:205-227

33. Bils RF, Christie BR 1980 Oxidant and air pollutant inhalation. Int Rev Exp Pathol 21:195-293

34. Müller B, Barth P, Von Wichert P 1992 Structural and functional impairment of surfactant protein $\mathrm{A}$ after exposure to nitrogen dioxide in rats. Am J Physiol 263:L177-L184

35. Sasidharan P, Nelin L, Thomas C, Dawson C 1993 Inhaled nitric oxide decreases airway resistance in the neonatal pig. Pediatr Res 33:386A (abstr)

36. Zayek M, Cleveland D, Morin III FC 1993 Treatment of persistent pulmonary hypertension of the newborn in the neonatal lamb by inhaled nitric oxide. $J$ Pediatr 122:743-750

37. Ehrlich R 1966 Effect of nitrogen dioxide on resistance to respiratory infection Bacteriol Rev 30:604-614

38. Murphy SD, Ulrich CE, Frankowitz SH, Xintraras C 1964 Altered function in animals inhaling low concentrations of ozone and nitrogen dioxide. Am Ind Hyg Assoc J 25:246-253

39. Dowell AR, Kilburn KH, Pratt PC 197! Short-term exposure to nitrogen dioxide effects on pulmonary ultrastructure, compliance and the surfactan system. Arch Int Med 128:74-80

40. Oda H, Nogami H, Kusumoto S, Nakajima T, Kurata A, Imai K 1976 Longterm exposure to nitric oxide in mice. J Jpn Soc Air Pollut 11:150-160

41. Stamler JS, Singel DJ, Loscalzo J 1992 Biochemistry of nitric oxide and its redox-activated forms. Science 258:1898-1902

42. Beckman JS, Beckman TW, Chen J, Marshall PA, Freeman BA 1990 Apparent hydroxyl radical production by peroxynitrite: implications for endothelial injury from nitric oxide and superoxide. Proc Natl Acad Sci USA 87:16201624

43. Radi R, Beckman JS, Bush KM, Freeman BA 1991 Peroxynitrite oxidation of sulfhydryls the cytotoxic potential of superoxide and nitric oxide. J Biol Chem 266:4244-4250

44. Radi R, Beckman JS, Bush KM, Freeman BA 1991 Peroxynitrite-induced membrane lipid peroxidation: the cytotoxic potential of superoxide and nitric oxide. Arch Biochem Biophys 288:481-487

45. Toothill $C 1967$ The chemistry and the in vivo reaction between haemoglobin and various oxides of nitrogen. Br J Anaesth 39:405-412

46. Maeda N, Imaizumi K, Kon K, Shiga T 1987 A kinetic study on functional impairment of nitric oxide exposed rat erythrocytes. Environ Health Perspect 73:171-177 